\title{
CORNELL MRS CONFERENCE
}

\author{
MRS Co-Sponsors International Conference On \\ 'Ion Beam Modification Of Materials' July 16-19
}

The Materials Research Society will for the first time cosponsor one in the series of international "Ion Beam Modification of Materials" conferences to be held this year on the campus of Cornell University, Ithaca, NY, July 1619. The MRS is hoping to forge continuing links to this sequence of materials conferences and is particularly pleased to begin with a conference guided by an international committee and chaired by Prof. J.W. Mayer, one of its own distinguished Von Hippel Award winners.

The 1984 conference is one in a series that began in 1970 at Thousand Oaks, when "Ion Implantation in

Semiconductors" was a new field. In 1978 in Budapest the conference organizers recognized the broadening scope of ion beam-solid interest and originated the title "Ion Beam Modification of Materials," which subsequent semi-annual meetings at Albany and Grenoble have also borne. The MRS is pleased to establish a co-sponsor relationship with these conferences since this field of research has already been recognized as important to the MRS. Several past MRS annual meetings have had symposia on closely related themes. The most recent was the one held this November in Boston, the symposium "Ion Implantation and Ion Beam Processing of Materials," which was organized by G.K. Hubler, C.R. Clayton, O.W. Holland, and C.W. White. [Ed. note: This symposium is reported elsewhere in this issue of the BULLETIN.]

The Cornell conference will have a four-day format. The scope, organization, and deadlines are indicated below.

The emphasis of the conference is on ion-induced changes in composition, structure, and defects and the associated changes in mechanical, electrical, optical, or chemical properties of metals, semiconductors, ceramics, and organic material. The conference is organized in the following sessions:

Metals 1 and 2 (S. Myers and P. Peercy)

Semiconductors 1 and 2 (B.R. Appleton, D.E. Davies, and J. Donnelly)

Sputtering Phenomena (H.H. Andersen)

Ion Mixing (S.S. Lau and M.A. Nicolet)

Polymers, Ceramics, And Other Insulators (W.L. Brown and J.A. Davies)

Ion Assisted Etching (J. Coburn)

Fine Line Structures (I. Adesida)

Invited and contributed papers will be presented in oral sessions, with the majority of contributed papers presented in poster sessions. The deadline for receipt of abstracts of contributed papers is March 1. Notification of acceptance will be made by April 2. Papers accepted for presentation

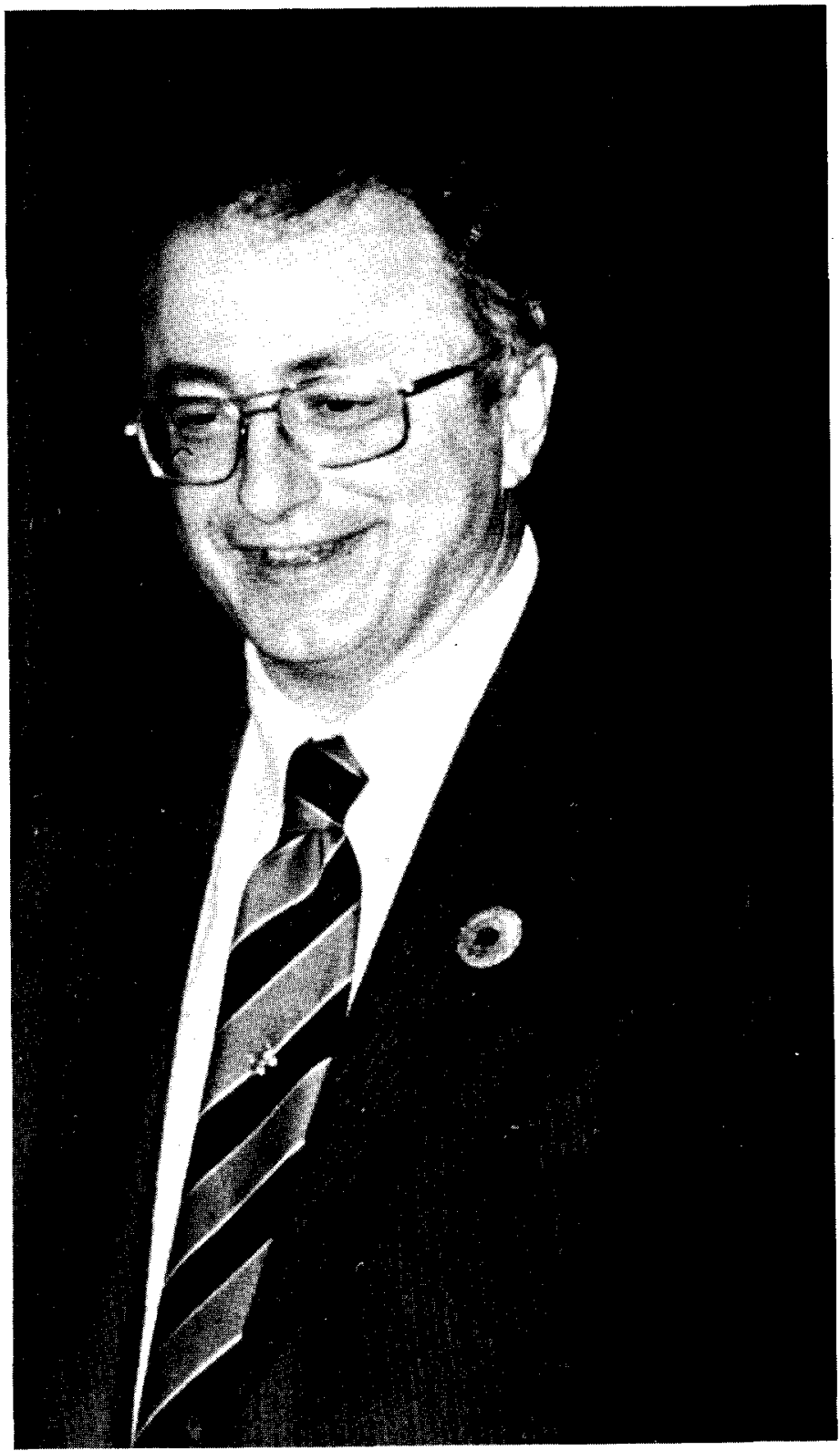

JAMES MAYER

at the conference may be accepted for publication in the conference proceedings after peer review.

For more information contact: Susan B. Hurwitz, Conference Secretary, IBMM '84, Bard Hall, Cornell University, Ithaca, N.Y 14853, (607) 256-5190. 